\title{
Education in pain
}

\section{Educação em dor}

The biomedical literature grows exponentially, and knowledge about molecular biology and immunology is expanding more rapidly ${ }^{1}$. Early diagnoses, the use of effective and safe therapies with favorable results are current requirements. This means that the advances in areas related to symptoms control and clinical decisions should be incorporated into the new modes of knowledge transmission and care of patients with pain ${ }^{2,3}$. The improvement of health education programs does not occur at the same speed in which knowledge multiplies. Many schools include descriptive themes in their curricula rather than analytical subjects and critical and logical thoughts ${ }^{4}$. However, since the publication of the model of medical graduation based on the Flexner report of $1912^{5}$, the teaching of health sciences has incorporated biocentric and technocentric visions. We started to study the human body by parts. The diseases are now considered biological, cellular and molecular malfunctioning. Medical schools were organized to train students in diseases, to be specialists working in hospitals but not trained to care patients and, consequently, physicians were stimulated and trained to perform physical or chemical interventions to normalize the functioning of the body with an insufficient notion of the individual as a whole and in the society ${ }^{6}$.

Some medical and paramedical concepts and practices are kept alive and widely disseminated and performed because they are truly useful, safe and effective. However, many are still used and will remain indefinitely, even without any evidence, substrates or grounds justifying their applicability because they sustain, adapt and surreptitiously propagate themselves based on poorly elaborated concepts about their realities ${ }^{7}$ This means that the awareness, dissemination and strategic use of good quality information can make a significant contribution so that, in future, the procedures that aim at the prevention and control of pain are used in a rational way and without the biases of traditions and interests other than the benefit of those who suffer from pain ${ }^{7,8}$. The meaning of medicine in the society and the relationship between health professionals, health policymakers and patients undergo constant change. The content and dissemination of medical curricula also evolve to ensure consistent delivery of high-quality medical services. Therefore, having the curriculum as an institutional educational proposal with the objective of informing, executing and evaluating educational programs with an ordered sequence of contents, and making appropriate use of the media to make public the scientific achievements and the rational application of health policies can contribute to revert this trend, both for the general population and for the professionals involved in the planning, prevention and treatment of pain'. We see progress in the areas of education, training, accreditation of professionals and care services in parallel with advances in pharmacology, rehabilitation, psychotherapy, and interventional pain procedures. Practitioners working in environments designated for primary care currently have the opportunity to receive good quality training on more common issues related to pain in undergraduate courses and symposiums organized by official and associative entities, without the influence of entities concerned only with profit. The creation of the Pain Leagues, the incorporation of the theme of pain in the undergraduate and graduate medical and paramedical curricula and in the university extension courses, the organization of internship programs in pain in the areas of medicine, dentistry, veterinary and psychology, fulfilled, in part, the needs of technical pain training with comprehensive information, provided that interventions are not the predominant or exclusive focus. Professionals dedicated to the treatment of pain working in clinics, isolated units, clinics or specialized centers should more significantly incorporate mental health, rehabilitation and education programs in the treatment, especially of chronic wild pain. For specialized professionals, simulation techniques have been developed to improve the skills to perform invasive or non-invasive procedures and, at the same time, better-founded guidelines have been developed for the application of prophylactic methods, drugs and invasive or non-invasive interventions in patients with pain ${ }^{6}$. There is an increasing number of studies on health education and controlled research with random samples on prevention, effectiveness of new drugs and therapeutic models, combinations of treatments with other interventions, the connection of therapeutic models with the mechanisms of pain responsible for different pain syndromes, identification of predictors of therapeutic responses, adequacy of treatments or characteristics of treatments to the individual characteristics of patients, and long-term maintenance of the positive responses to treatment of appropriately selected patients ${ }^{10,11}$.

Manoel Jacobsen Teixeira
Universidade de São Paulo, Faculdade de Medicina,
Departamento de Neurologia, São Paulo, SP, Brasil.
E-mail: manoeljacobsen@gmail.com
Lin Tchia Yeng
Universidade de São Paulo, Faculdade de Medicina,
Departamento de Fisiatria, Clinica de Funcionalidade e Dor, São Paulo, SP, Brasil.
E-mail: grupodedor@gmail.com

(c) Sociedade Brasileira para o Estudo da Dor 


\section{REFERENCES}

1. Boulos M. Objetivos do ensino médico. Documentos CEDEM FMUSP; 1994. 45-54p.

2. O'Donnell JF, Baron JA. A strategy to teach medical decision making within a medical school curriculum. J. Cancer Educ. 1991;6(3):123-8.

3. Saunders DC. The evolution of the hospices. In: The history of the management of pain: from early principles to present practice. [S.I.]: Carnforth, Lancs, Pathernnon P. Group, 1988. 167-78p.

4. Flexner A. Medical Education in the United States and Canada: A Report to the Carnegie Foundation for the Advancement of Teaching, Bulletin $N^{\circ} 4$, New York City: The Carnegie Foundation for the Advancement of Teaching; 1910.

5. Conferência Internacional dobre Cuidados Primários de Saúde Alma-Ata, URSS, 6-12 de setembro de 1978
6. Pimenta CA, Teixeira MJ, Simóes P, Simóes C, da Cruz Dde A, Okada M. [League against pain: an experiment in extracurricular teaching]. Rev Esc Enferm USP. 1998;32(3):281-9. Portuguese.

7. Moritz E. Memetic science: I. General introduction. J Ideas. 1990;1:1-23.

8. Moritz E. Metasystems, memes and cybernetic immortality. In: Heylighen F, Joslyn C, Turchin V, eds. The quantum of evolution: toward a theory of metasystem transitions. New York: Gordon \& Breach Science Publishers; 1995. 155-71p.

9. Frenk J, Chen L, Bhutta ZA, Cohen J, Crisp N, Evans T, et al. Health professionals for a new century: transforming education to strengthen health systems in an interdependent world. Lancet. 2010;376(9456):1923-58.

10. Carr DB, Cousins MJ. Trends in pain management 1987-1996: an evidence-based survey. Curr Opin Anaesthesiol. 1997;10(5):xliii-xlvi.

11. Worley SL. New directions in the treatment of chronic pain national pain strategy will guide prevention, management, and research. PT. 2016;41(2):107-14. 